\title{
ИССЛЕДОВАНИЕ ВЛИЯНИЯ РАЗВИТИЯ УЛИЧНО-ДОРОЖНОЙ СЕТИ НА РЫНОЧНУЮ СТОИМОСТЬ НЕДВИЖИМОГО ИМУЩЕСТВА
}

\section{Алексей Викторович Дубровский}

Сибирский государственный университет геосистем и технологий, 630108, Россия, г. Новосибирск, ул. Плахотного, 10, кандидат технических наук, зав. кафедрой кадастра и территориального планирования, тел. (383)361-01-09, e-mail: avd5@ssga.ru

\section{Фарид Ринатович Усманов}

Сибирский государственный университет геосистем и технологий, 630108, Россия, г. Новосибирск, ул. Плахотного, 10, обучающийся, тел. (383)361-01-09, e-mail: usmanov_fara@mail.ru

Формирование дорожно-транспортной системы является одним из главных направлений развития современных городов. Высокий уровень развития транспорта - это большое преимущество, которое позволяет населению быстро добираться в любую точку города. В связи с этим ценность территорий с развитой транспортной инфраструктурой увеличивается по сравнению с теми, где она развита в меньшей степени. Такое различие отражается, в том числе и в цене на недвижимость. К настоящему времени проведено достаточно много эмпирических исследований по данному вопросу. Однако результаты разных исследований значительно отличаются и иногда противоречат друг другу. Кроме того, влияние факторов транспортной доступности на цену недвижимости имеет неодинаковое влияние в разных регионах, что приводит к необходимости проведения исследований для каждого города в отдельности. Для того чтобы определить степень влияния улично-дорожной сети на рыночную стоимость недвижимости необходимо выполнить анализ факторов, влияющих на стоимость недвижимости, и сравнить объекты-аналоги. Для проведения анализа, были взяты земельные участки из жилых комплексов Новосибирска, имеющих разные характеристики. Получены практические данные подтверждающие влияние уровня развития улично-дорожной сети на рыночную стоимость недвижимости на территории города Новосибирска.

Ключевые слова: улично-дорожная сеть, транспортная инфраструктура, рыночная стоимость, рациональное использование земельных ресурсов, генеральный план развития города

\section{STUDY OF THE INFLUENCE OF DEVELOPMENT OF THE STREET AND ROAD NETWORK ON THE MARKET VALUE OF REAL ESTATE}

\section{Alexey V. Dubrovsky}

Siberian State University of Geosystems and Technologies, 10, Plakhotnogo St., Novosibirsk, 630108, Russia, Ph. D., Head of the Department Cadastre and Territorial Planning, phone: (383)361-01-09, e-mail: avd5@ssga.ru

\section{Farid R. Usmanov}

Siberian State University of Geosystems and Technologies, 10, Plakhotnogo St., Novosibirsk, 630108, Russia, Student, phone: (383)361-01-09, e-mail: usmanov_fara@mail.ru

The formation of a well-functioning road transport system is one of the main directions for the development of modern cities. The high level of transport development is a great advantage that allows the population to quickly get to any point in the city. In this regard, the value of territories with 
a developed transport infrastructure increases compared to those where it is less developed, which is mainly reflected in the price of real estate in this territory. To date, a lot of empirical studies have been carried out on this issue. However, the results of different studies differ significantly and sometimes contradict each other. In this regard, the study of this subject area requires more careful consideration. In addition, interest in this topic is due to the fact that most often the influence of transport accessibility factors on the price of real estate has an unequal effect in different regions, which leads to the need to conduct research for each city separately. In order to determine the degree of influence of the UDS on the market value, you need to analyze it. For the analysis, land plots were taken from residential complexes with different characteristics.

Keywords: road network, road transport system, infrastructure, market value, rational use of land resources, master plan for the development of the city

Из теории оценки стоимости недвижимости известно, что на рыночную стоимость земельных участков и расположенной на них жилой недвижимости влияют следующие группы факторов [1-3]:

- местоположение земельного участка;

- демографические особенности населения, т.е. его структура, плотность, численность, состав, имеющаяся система расселения, уровень экономического благополучия и т.д.;

- особенности государственного обеспечения земельно-имущественных отношений и гарантий прав собственников недвижимости (нормативно-правовое обеспечение земельно-имущественных отношений, нормы публичного и частного права, сервитуты, градостроительные и природоохранные режимы, требования по уплате налогов и т.д.);

- природные особенности и окружающая среда, например климат, красивый вид или ландшафт, наличие рекреационных зон и т.д.;

- физические характеристики участка, форма и рельеф участка, его инженерная подготовка, плотность застройки;

- близость к транспортной инфраструктуре и наличие удобно спроектированной улично-дорожной сети (УДС).

Транспортная инфраструктура города - это одна из основных характеристик удобства проживания населения. Мегаполисы, в которых нет дорожных затруднений, являются эталонами градостроительства. Однако при этом транспортные проблемы не смогли решить даже такие города, как Лондон, Лос-Анжелес, Штутгарт, Брюссель [4].

Для того чтобы определить степень влияния УДС на рыночную стоимость недвижимости, нужно выполнить анализ основных стоимостных факторов. Для проведения анализа, были взяты земельные участки из жилых комплексов города Новосибирска, имеющих разные характеристики. Статистические данные, используемые в дальнейшем для проведения анализая, представлены в табл. 1 [5]. 
Таблица 1

\begin{tabular}{|c|c|c|c|c|c|}
\hline $\begin{array}{c}\text { Название жилого } \\
\text { комплекса }\end{array}$ & $\begin{array}{c}\text { Удаленность } \\
\text { от географи- } \\
\text { ческого цен- } \\
\text { тра города } \\
\text { (км) }\end{array}$ & $\begin{array}{c}\text { Удаленность } \\
\text { от культур- } \\
\text { ного центра } \\
\text { города (км) }\end{array}$ & $\begin{array}{c}\text { Расстояние } \\
\text { до ближай- } \\
\text { шей стан- } \\
\text { ции метро } \\
\text { (км) }\end{array}$ & $\begin{array}{c}\text { Уровень каче- } \\
\text { ства запроек- } \\
\text { тированной } \\
\text { УдС }\end{array}$ & $\begin{array}{c}\text { Класс } \\
\text { стройки }\end{array}$ \\
\hline Чистая слобода & 9.4 & 8.7 & 5.8 & высокий & эконом \\
\hline Новый горский & 4.3 & 4.4 & 1.1 & высокий & эконом \\
\hline Шевченковский & 2.7 & 1.6 & 0.3 & средний & эконом \\
\hline Рихард & 7.7 & 10.7 & 5.9 & низкий & бизнес \\
\hline Плющихинский & 5.8 & 7 & 3.4 & низкий & эконом \\
\hline
\end{tabular}

На рисунке показана схема расположения выбранных для эксперимента участков жилой застройки на территории города Новосибирска.

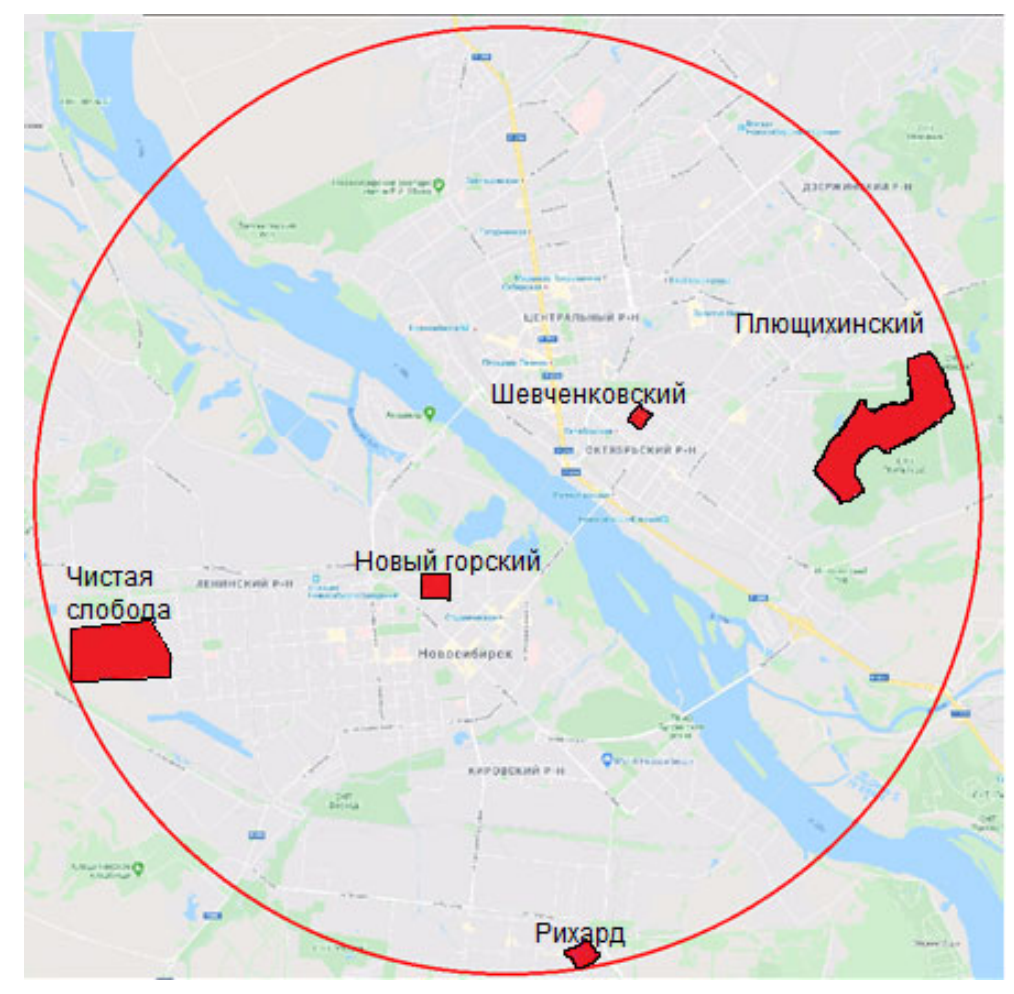

Схема расположения жилых комплексов

Данные о средней рыночной стоимости жилой недвижимости получены путем статистического анализа. Сравнение цен жилой недвижимости, расположенных на территориях выбранных жилых районов, приведено в табл. 2 [6]. Вид разрешенного использования для выбранных земельных участков «Для многоэтажной жилой застройки». 
Таблица 2

\begin{tabular}{|c|c|c|c|}
\hline Наименование & Кадастровый номер & $\begin{array}{c}\text { Площадь 3У } \\
\text { (м. кв.) }\end{array}$ & $\begin{array}{c}\text { Средняя рыночная стоимость 1 } \\
\text { кв. м. жилой недвижимости на } \\
\text { данном 3У руб/м }\end{array}$ \\
\hline Чистая слобода & $54: 35: 062535: 3024$ & 6918 & 88118 \\
\hline Новый горский & $54: 35: 071585: 1944$ & 6956 & 69212 \\
\hline Шевченковский & $54: 35: 064285: 71$ & 7670 & 94321 \\
\hline Рихард & $54: 35: 073055: 3$ & 12074 & 97768 \\
\hline Плющихинский & $54: 35: 051950: 9$ & 7244 & 69118 \\
\hline
\end{tabular}

При проведении сравнения жилых комплексов Чистая слобода и Плющихинский, несмотря на то, что некоторые ценообразующие факторы второго оцениваемого микрорайона выше, УДС Чистой слободы значительно превосходит по эффективности УДС Плющихинского жилмассива. Транспортная доступность Чистой слободы оценивается как «высокая». При этом средняя стоимость недвижимости на территории этих двух микрорайонов отличается на 27\%. Данные и результат сравнения представлены в табл. 3.

Таблииа 3

\begin{tabular}{|c|c|c|}
\hline $\begin{array}{c}\text { Название жимассива / Ценообразующие факторы и } \\
\text { цены }\end{array}$ & Чистая слобода & Плющихинский \\
\hline Расстояние до культурно-исторического центра (км) & 8.7 & 7 \\
\hline Расстояние до географического центра (км) & 9.4 & 5.8 \\
\hline Расстояние до ближайшей станции метро (км) & 5.8 & 3.4 \\
\hline Класс жилой застройки & эконом & эконом \\
\hline Уровень развития УДС & высокий & низкий \\
\hline Социальная инфраструктура & развита & развита \\
\hline $\begin{array}{c}\text { Рыночная стоимость } 1 \text { кв.м. жилого помещения } \\
\text { (руб. на кв.м.) }\end{array}$ & 88118 & 69212 \\
\hline \multicolumn{2}{|l|}{ Разница рыночной стоимости 1 кв.м. (\%) } & $27 \%$ \\
\hline
\end{tabular}

31 марта 2020 года в Генеральный план города Новосибирска были внесены ряд изменений, дополнений и поправок [7 - 9]. Было запланировано строительство и оптимизация УДС Новосибирска. По данным генерального плана до 2030 года планируется строительство улицы Доватора до улицы Выборной, проходить она будет через Плющихинский жилмассив с противоположной стороны от уже имеющегося выезда. Это должно значительно упростить и уменьшить транспортную нагрузку на УДС этого района. В результате прогнозируется увеличение спроса на жилую недвижимость и рост ее рыночной стоимости. При этом, генеральный план не полностью решает проблему транспортного обеспечения данного микрорайона, так как улица Выборная имеет выезд на улицу Большевистскую, которая является главным магистральным выездом на Бердское шоссе 
и является постоянно загруженным автотранспортом участком, на котором замедляется поток выезда и въезда в город.

Далее проведено сравнение жилмассивов Новый Горский и Шевченковский. Ценообразующие факторы жилой недвижимости Нового Горского немного, но все же уступают Шевченковскому (сказывается левобережное расположение микрорайона и удаленность от центра города), однако, качественно спроектированная УДС вокруг Нового Горского микрорайона компенсирует данный недостаток, так как имеется множество выездов на крупные дорожные развязки, ведущие к Октябрьскому и Демитровскому мостам. Этим объясняется несущественная разница цен на жилую недвижимость. Результат сравнения представлены в табл. 4.

Таблицза 4

\begin{tabular}{|c|c|c|}
\hline $\begin{array}{c}\text { Название жимассива / Ценообразующие факторы и } \\
\text { цены }\end{array}$ & Новый горский & Шевченковский \\
\hline Расстояние до культурно-исторического центра (км) & 4.4 & 1.6 \\
\hline Расстояние до географического центра (км) & 4.3 & 2.7 \\
\hline Расстояние до ближайшей станции метро (км) & 1.1 & 0.3 \\
\hline Класс жилой застройки & эконом & эконом \\
\hline Уровень развития УДС & высокий & средний \\
\hline Социальная инфраструктура & развита & развита \\
\hline Рыночная стоимость 1 кв. м. жилого помещения & & 97768 \\
\hline \multicolumn{2}{|c|}{ (руб. на кв. м.) } & 94321 \\
\hline
\end{tabular}

Далее были проведены сравнения Нового Горского с Чистой слободой. Основное отличие недвижимости расположенной в Новом Горском, заключается в том, что данный жилмассив располагается значительно ближе к центру, чем Чистая слобода. Остальные ценообразующие факторы отличаются не существенно. Можно предположить, что влияние на разницу в стоимости, составляющую 7\%, оказывает преимущественно географическое расположение. Данные и результат сравнения представлены в табл. 5.

Таблицุа 5

\begin{tabular}{|c|c|c|}
\hline $\begin{array}{c}\text { Название жимассива / Ценообразующие факторы и } \\
\text { цены }\end{array}$ & Чистая слобода & Новый горский \\
\hline Расстояние до культурно-исторического центра (км) & 8.7 & 4.4 \\
\hline Расстояние до географического центра (км) & 9.4 & 4.3 \\
\hline Расстояние до ближайшей станции метро (км) & 5.8 & 1.1 \\
\hline Класс жилой застройки & эконом & эконом \\
\hline Уровень развития УдС & высокий & высокий \\
\hline Социальная инфраструктура & развита & развита \\
\hline Рыночная стоимость 1 кв.м. жилого помещения \\
(руб. на кв.м.)
\end{tabular}

Разница между Шевченковским и Плющихинским жилмассивами заключается как в качестве УДС, так и географическом расположении, которое, исходя из 
данных предыдущего сравнения составляет примерно 10\%. Данные и результат сравнения представлены в табл. 6. Соответственно недостаточно развитая УДС влияет на разницу стоимости в $31 \%$. Отсюда следует, что после строительства улицы Доватора, запланированного в генеральном плане, разница стоимости уменьшится и будет составлять менее $10 \%$, что обусловлено географическим положением. Примерная расчетная рыночная стоимость 1 кв. м. жилой площади в Плющихинском жилмассиве будет составлять 89975 рублей, что примерно соответствует современной стоимости жилой недвижимости в Чистой слободе.

Таблицุа 6

\begin{tabular}{|c|c|c|}
\hline Название жимассива / Ценообразующие факторы и цены & Шевченковский & Плющихинский \\
\hline Расстояние до культурно-исторического центра (км) & 1.6 & 7 \\
\hline Расстояние до географического центра (км) & 2.7 & 5.8 \\
\hline Расстояние до ближайшей станции метро (км) & 0.3 & 3.4 \\
\hline Класс жилой застройки & эконом & эконом \\
\hline Уровень развития УДС & средний & низкий \\
\hline Социальная инфраструктура & развита & развита \\
\hline $\begin{array}{c}\text { Рыночная стоимость 1 кв.м. жилого помещения (руб. на } \\
\text { кв.м.) }\end{array}$ & 97768 & 69212 \\
\hline Разница рыночной стоимости 1 кв.м. (\%) & \multicolumn{2}{|c|}{$41 \%$} \\
\hline
\end{tabular}

В качестве примера, был также рассмотрен жилой комплекс Рихард. Его ценообразующие факторы идентичны Чистой слободе (одинаковая отдаленность от метро, географического и культурно-исторического центров). Но УДС вокруг него, имеет множество недостатков, и поэтому, несмотря на то, что это жилая зона бизнес класса, цена на 28\% ниже, чем в Чистой слободе, т.е. абсолютно идентична ценам в Плющихинском жилмассиве.

Проведенные сравнения показывают, что проектирование и строительство хорошо функционирующей улично-дорожной сети - это главный аспект не только развития современного города, но и повышенного спроса на недвижимость и ее ценовой рост. Качественно функционирующая дорожная сеть обеспечивает быстрое и безопасное перемещение населения по территории города, что влияет на ценность территорий и отражается на стоимости недвижимости. На примерах проанализированных жилых районов следует, что рыночная стоимость недвижимости под влиянием улично-дорожной сети может изменяться. Сравнительный анализ показал, что качество УДС может влиять на рыночную стоимость недвижимости на территории города Новосибирска в диапазоне до 30 \%, как увеличивая, так и снижая ее.

\section{БИБЛИОГРАФИЧЕСКИЙ СПИСОК}

1. Грахова, Е.В. Анализ ценообразующих факторов на рынке жилой недвижимости в 2018 году [Текст] / Е.В. Грахова, Д.А. Агафонова, Д.В.Наольских - Вестник Челябинского Государственного Университета №12(422) - 2018 - С. 124-131.

2. Дубровский, А.В. К вопросу совершенствования системы оценки недвижимого имущества на основе расчета показателя социальной комфортности, А.В. Дубровский, Е.Д. Подрядчикова, Известия высших учебных заведений. Раздел: геодезия и аэрофотосъемка № 4/с. М.: МИИГАИК, 2014. - С. 153-157.

3. Грязновой, А. Г. Оценка недвижимости [Текст] / А. Г. Грязновой, М. А. Федотовой // Фин. акад. при правительстве Рос. Федерации. - М.: Финансы и статистика, 2003. - 492. 
4. Вучик, В.Р. Транспорт в городах, удобных для жизни [Текст] / Вучик В.Р// М.: Территория будущего - $2011-820 \mathrm{c}$.

5. Дубровский, А.В. Исследование с использованием ГИС взаимосвязи плотности улично-дорожной сети с плотностью застройки различных функциональных зон на примере города Новосибирска [Текст] / Дубровский А.В., Ершов А.В., Середович С.В. - Усть-Каменогорск, Международная конференция «Инновации и ГИС технологии для развития территорий». - Новосибирск: 2014. - С. 10-15.

6. Продажа недвижимости [Электронный ресурс] / NGS N1 - Режим доступа: https://novosibirsk.n1.ru/ - Загл. с экрана.2.

7. Генеральный план развития города Новосибирска [Электронный ресурс] / Департамент строительства и архитектуры мэрии города Новосибирска - Режим доступа: http://dsa.novo-sibirsk.ru/ru/site/1311.html - Загл. с экрана.

8. Кондратьев, А.В. Основные принципы совершенствования удично-дорожной сети Новосибирска [Текст] / Кондратьев А.В., Молчанов В.С., Попов А.М. // Вопросы технических наук в свете современных исследований: сб. ст. по матер. I междунар. науч.-практ. конф. № 1(1). - Новосибирск: СибАК, 2017. - С. 57-63.

9. Об утверждении государственной программы Новосибирской области «Развитие автомобильных дорог регионального, межмуниципального и местного значения в Новосибирской области». Постановление Правительства Новосибирской области от 23.01.2015г. №22-П (с изм. от 28.01.2020г.) [Электронный ресурс] / Электронный фонд - Режим доступа: http://docs.cntd.ru/document/465708078 - Загл. с экрана.

(С) А. В. Дубровский, Ф. Р. Усманов, 2021 